\title{
Long-term outcome of laparoscopic and open surgery in patients with Crohn's disease
}

This article was published in the following Dove Press journal:

Open Access Surgery

7 November 2017

Number of times this article has been viewed

\author{
Martin Hoffmann' \\ Dina Siebrasse' \\ Erik Schlöricke ${ }^{2}$ \\ Ralf Bouchard' \\ Tobias Keck' \\ Claudia Benecke' \\ 'Department of Surgery, University \\ Medical Center Schleswig-Holstein, \\ Campus Lübeck, Lübeck, ${ }^{2}$ Department \\ of Surgery, Westküstenklinikum Heide, \\ Heide, Germany
}

Aim: To investigate, via data analysis, the long-term outcome of patients who underwent either laparoscopic or open surgery for Crohn's disease.

Methods: A total of 113 patients who had undergone first abdominal surgery due to Crohn's disease between January 2000 and December 2010 in a maximum care provider facility, were included in the statistical analysis. All patients provided their informed consent prior to inclusion. Data were collected from a database. Follow-up data included data from central mortality registries, general practitioners and a specialized clinic. Statistical analysis of the general patient data and the different operations and approaches were performed with the use of chi-square test, Fisher's exact test, and the Mann-Whitney $U$ test.

Results: The median follow-up period in case of open and laparoscopic surgery was found to be 9 and 6 years, respectively. Statistically significant differences were observed for the following parameters in case of open and laparoscopic surgery, respectively: age (median=44 vs. 36 years, range $=15-76$ vs. $15-72$ years; $p=0.007$ ), urgency of operation ( 23 out of 34 planned vs. 6 out of 70 planned; $p<0.001$ ), year of resection (median $=2003$ vs. 2006 , range $=2000-2010$ vs. 2000-2010; $p=0.001$ ). The length of stay in hospital was significantly shorter in the laparoscopic group than that of open surgery group ( 8 vs. 11 days, respectively; $p<0.0001$ ). We did not control for factors such as age and comorbidities in our statistical analysis. We also did not find any differences with regard to perioperative and 90-day mortality, surgical complications, length of specimen, stoma, surgical recurrence rate (10\% in both groups) and number of re-admissions. Moreover, we did not find differences between patients with early operation after first symptoms and patients with long course of disease. A statistically significant difference was found for long-term mortality that was higher in the open surgery group than that of laparoscopic group $(p=0.005$ ) (the median for open surgery group was significantly higher than that of laparoscopic group).

Conclusion: The outcome of laparoscopic and open surgery is at least comparable. Shorter length of hospital stay and comparable surgical recurrence rates are advantages of laparoscopy.

Keywords: Crohn's disease, follow-up, retrospective, laparoscopic, open, outcome

\section{Introduction}

Despite pronounced progress in conservative therapy, patients with Crohn's disease often need abdominal surgery in the event of intestinal strictures, perforations and inflammatory pseudo-tumors. Laparoscopic and open resections are both established therapeutic options with a growing number of planned laparoscopic resections especially in young patients. ${ }^{1}$ The goal of any surgery is not to cure the disease but to regain the quality of life of patients undergoing surgery. ${ }^{2,3}$ 
Crohn's disease is a common pathology with about 6.6 new patients/100,000 inhabitants per year. The prevalence of this disease is significantly higher in the "western" countries with several hundred cases identified per 100,000 inhabitants every year. Bowel sparing resections or plastic intestinal strictures are now standard of care and are associated with a lower risk of short bowel syndrome. ${ }^{4}$ About $50 \%$ of the patients who undergo surgery develop surgical recurrence within 10 years after the initial surgery. ${ }^{5}$ To allow a redo surgery, the trauma of the operative access should be as small as possible to prevent the development of dense intraabdominal adhesions. ${ }^{6}$ Because of the smaller trauma and better cosmetic results, ${ }^{6}$ the laparoscopic access has been implemented into the surgical therapy for Crohn's disease during the last decades.

We analyzed our data of 113 patients who were treated with either open or laparoscopic surgery to compare their perioperative and long-term outcome.

\section{Materials and methods}

The study included 133 patients who underwent intestinal resection due to Crohn's disease between 1 January 2000 and 31 December 2010. Patients were included if they had Crohn's disease proven with intestinal biopsy and had not undergone any prior abdominal surgery. Patients who underwent operations because of extra-abdominal manifestation of the disease were not included in the analysis. In addition to the general patient data such as age, gender and year of operation, the database was continuously updated with the follow-up data from our clinic and general practitioners. Moreover, data from central mortality registries was also included.

\section{Statistical analysis}

We used IBM SPSS version 20.0 software (IBM Corp, 2011) for the data analysis. The general patient data were analyzed, and we performed chi-square test, Fisher's exact test and the Mann-Whitney $U$ test to compare the data between the open surgery and the laparoscopic group.

The ethics committee of the University of Lübeck approved the study protocol and the statistical analysis (Az: 12-078). All patients provided their informed consent prior to inclusion.

The following hypotheses were defined:

\section{Hypothesis I}

The two patient cohorts (laparoscopic surgery and open surgery) are not different with respect to age, gender, duration of disease, prior operations, acute symptoms, indication, emergency of operation and type of resection.

\section{Hypothesis $2 \mathrm{a}$}

Postoperative length of stay in hospital is shorter in laparoscopic group than that of open surgery group.

\section{Hypothesis $2 b$}

There are statistically significant differences between the two groups with respect to morbidity and mortality rates, prevalence of stoma and disease recurrence.

\section{Results}

\section{Preoperative patients' data}

Table 1 summarizes the data of the patients of the study cohort. It also shows the results of the statistical analysis for hypothesis 1 .

\section{General patient characteristics}

Majority of the patients ( 76 vs. 57 patients) underwent a laparoscopic surgery for Crohn's disease. There were no differences with respect to the gender distribution between the two groups. We found a higher proportion of women who underwent laparoscopic surgery, but the difference was not statistically significant.

Patients who underwent laparoscopic surgery were significantly younger at the time of their operation $(p=0.007)$; their median age was 36 years, whereas it was 44 years in the open surgery group. There were no differences with reference to the latency between initial diagnosis and first resection for Crohn's disease $(p=0.873)$. In patients who underwent open surgery, the median latency period was found to be 5.5 years, whereas in the laparoscopic group, it was 5 years. In 27 patients, we were not able to exactly evaluate the first manifestation of the disease.

\section{Year of resection}

The year of first resection was found to be highly different between the two groups, which was statistically significant $(p=0.001)$. Open resections dated back significantly longer together with a continuous increase in laparoscopic resections during the period analyzed. The median follow-up period for the open surgery group was 9 years, whereas it was 6 years for the laparoscopic group.

\section{Prior surgery}

Key inclusion criterion for the study was a first resection of any part of the intestine between January 2000 and December 
Table I Overall patient cohort

\begin{tabular}{|c|c|c|c|}
\hline & Open Surgery n=57 & Laparoscopic Surgery n=76 & $p$-value \\
\hline Age (years) ${ }^{d}$ & $44(15-76)$ & $36(15-72)$ & $0.007^{b *}$ \\
\hline Gender, n (\%) & & & $0.069^{\mathrm{a}}$ \\
\hline Male & $30(52.6 \%)$ & $28(36.8 \%)$ & \\
\hline Female & 27 (47.4\%) & 48 (63.2\%) & \\
\hline Time since diagnosis (years) $)^{\mathrm{d}, \mathrm{e}}$ & $5.5(0-35)$ & $5(0-28)$ & $0.873^{\mathrm{b}}$ \\
\hline Year of resection (year) ${ }^{d}$ & $2003(2000-2010)$ & $2006(2000-2010)$ & $0.00 I^{b *}$ \\
\hline Prior surgeries, n (\%) & & & $0.164^{c}$ \\
\hline Fistula operation (validated) & $5(8.8 \%)$ & $5(6.6 \%)$ & \\
\hline No operations (validated) & $42(73.7 \%)$ & 65 (85.5\%) & \\
\hline Unknown fistula operation ${ }^{f}$ & $10(17.5 \%)$ & $6(7.9 \%)$ & \\
\hline \multicolumn{4}{|l|}{ Symptoms, n (\%) } \\
\hline Pain & 47 (82.5\%) & $62(81.6 \%)$ & $0.896^{a}$ \\
\hline Changes in defecation & $25(43.9 \%)$ & $44(57.9 \%)$ & $0.109^{\mathrm{a}}$ \\
\hline Blood discharge & $\mathrm{I}(\mathrm{I} .8 \%)$ & $9(11.8 \%)$ & $0.043^{c *}$ \\
\hline Fever & $18(31.6 \%)$ & $8(10.5 \%)$ & $0.002^{\mathrm{a} *}$ \\
\hline Loss of body weight & $12(21.1 \%)$ & II (I4.5\%) & $0.32 I^{\mathrm{a}}$ \\
\hline Hypoproteinemia & $9(15.8 \%)$ & $3(3.9 \%)$ & $0.029 *$ \\
\hline Leucocytosis & $32(56.1 \%)$ & $29(38.2 \%)$ & $0.039^{a *}$ \\
\hline Elevated CRP & 39 (68.4\%) & 37 (48.7\%) & $0.023^{\mathrm{a} *}$ \\
\hline Nausea & $14(24.6 \%)$ & $10(13.2 \%)$ & $0.091^{\mathrm{a}}$ \\
\hline Other & $19(33.3 \%)$ & $22(28.9 \%)$ & $0.588^{a}$ \\
\hline \multicolumn{4}{|l|}{ Indication, n (\%) } \\
\hline Stenosis & $33(57.9 \%)$ & $57(75.0 \%)$ & $0.037^{a *}$ \\
\hline Bleeding & $\mathrm{I}(\mathrm{I} .8 \%)$ & $6(7.9 \%)$ & $0.235^{c}$ \\
\hline lleus & $7(12.3 \%)$ & $6(7.9 \%)$ & $0.399^{\mathrm{a}}$ \\
\hline Perforation & $13(22.8 \%)$ & $7(9.2 \%)$ & $0.030^{a *}$ \\
\hline Peritonitis & $24(42.1 \%)$ & $12(15.8 \%)$ & $0.00 I^{c *}$ \\
\hline Sepsis & $6(10.5 \%)$ & $\mathrm{I}(\mathrm{I} .3 \%)$ & $0.042^{c *}$ \\
\hline Failure of conservative therapy & $5(8.8 \%)$ & $21(27.6 \%)$ & $0.007^{2 *}$ \\
\hline Urgency of operation, n (\%) & & & $<0.00 I^{\text {a* }}$ \\
\hline Acute & $23(40.4 \%)$ & $6(7.9 \%)$ & \\
\hline Planned & $34(59.6 \%)$ & $70(92.1 \%)$ & \\
\hline Type of operation, n (\%) & & & $0.094^{\mathrm{a}}$ \\
\hline lleocecal resection & $24(42.1 \%)$ & $36(47.4 \%)$ & \\
\hline Colectomy & $19(33.3 \%)$ & $32(42.1 \%)$ & \\
\hline Other (small bowel) & $14(24.6 \%)$ & $8(10.5 \%)$ & \\
\hline
\end{tabular}

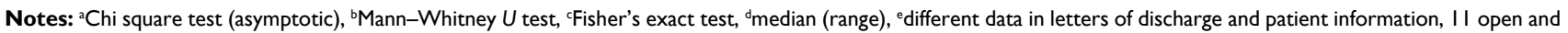
16 laparoscopic patients, 'no exact documentation on fistula operations performed, *statistically significant.

Abbreviation: CRP, C-reactive protein.

2010. There were patients in both groups who underwent prior surgery for anal fistulas. As shown in Table 1, 6.6\% of the patients in the laparoscopic group and $8.8 \%$ of the patients in the open surgery group underwent prior surgery, which was found to be minor. In majority of the patients, the abdominal surgery in our department was the first operation in both groups ( $73.7 \%$ open vs. $85.5 \%$ laparoscopic surgery). We did not have exact data on the type of surgery performed to treat anal fistula in at least 16 patients. Nevertheless, in these 16 patients, the laparoscopic or open resection in our department was their first abdominal surgery.

\section{Symptoms}

Table 1 shows the prevalence of typical symptoms associated with Crohn's disease in both groups (pain [both about 80\%], changes in defecation [ $43.9 \%$ open vs. $57.9 \%$ laparoscopic surgery] and weight loss [21.1\% open vs. $14.5 \%$ laparoscopic surgery]). Significant differences were observed between the two groups with regard to clinical and laboratory markers of inflammation. Patients in the open surgery group had significantly higher prevalence of fever $(p=0.002)$, elevated leukocyte count $(p=0.039)$ and elevated $\mathrm{C}$-reactive protein (CRP) ( $p=0.023)$ than that of laparoscopic group. Another important laboratory parameter that had a significantly higher prevalence in the open surgery group than that of laparoscopic group was hypo-proteinemia $(p=0.029)$.

\section{Indication}

Intestinal stenosis was the primary reason for surgical resection in both groups. Both groups were significantly different with 
about $70 \%$ of the patients in laparoscopic group undergoing an operation due to intestinal stenosis $(p=0.037)$. The second leading cause in the laparoscopic group was failure of conservative medical therapy (27.6\%), whereas this indication was very rare in the open surgery group $(8.8 \%)$; the difference between the groups was found to be highly statistically significant $(p=0.007)$. Sepsis $(p=0.042)$, perforation $(p=0.030)$ and peritonitis ( $p=0.001$ ) were also the indications for an open surgery, which were also found to be significant. Ileus and recurrent intestinal hemorrhage were rare indications in both groups. A statistically significant difference was also found with respect to the urgency of the operation $(p \leq 0.001)$. Operations with high urgency were more commonly performed via open access, which was significantly higher than that of laparoscopic surgery.

\section{Type of operation}

There were no differences between the two groups with regard to extent and localization of resection $(p=0.094)$. Ileocecal resections were the most commonly performed resections in both groups, with colectomies as the second most common surgical intervention.

\section{Testing of hypothesis I}

During the testing of hypothesis 1 , we found that the differences in factors such as age, symptoms, indication, urgency of operation and year of resection between the two groups were statistically significant.

\section{Postoperative outcome}

Table 2 shows the results of the analysis of the data on postoperative outcome. In addition, the results of the analyses with respect to hypotheses $2 \mathrm{a}$ and $2 \mathrm{~b}$ are presented.

\section{Length of stay}

Patients with laparoscopic interventions had a median length of hospital stay at the hospital of 8 days after the index operation. Patients in the open surgery group had a significantly longer period of hospitalization with a median of 11 days $(p<0.001)$. There were patients in both groups with very prolonged hospitalizations of up to 4 months without any significant difference between the groups related to the surgery.

\section{Long-term survival}

There was a statistically significant difference between the groups with regard to mortality during the long-term followup. While only $3.9 \%$ of the patients in the laparoscopic group had an adverse outcome, $15.8 \%$ of the patients in the open surgery group had an adverse outcome in the long-term follow-up ( $p=0.005)$. The perioperative 90-day mortality was not different between the two groups.

Table 2 Overall patient cohort, patient characteristics after open vs. laparoscopic intestinal resection in patients with Crohn's disease

\begin{tabular}{|c|c|c|c|}
\hline Postoperative & Open Surgery $n=57$ & Laparoscopy $n=76$ & $p$-value \\
\hline Length of stay (days) ${ }^{d}$ & $13(8-255)$ & II (6-II9) & $0.009^{b *}$ \\
\hline Length of postoperative stay (days) ${ }^{d}$ & II (5-239) & $8(6-115)$ & $>0.00 I^{b *}$ \\
\hline \multicolumn{4}{|l|}{ Complications, n (\%) } \\
\hline No & $38(66.7 \%)$ & 59 (77.6\%) & $0.159^{a}$ \\
\hline Yes & 19 (33.3\%) & 17 (22.4\%) & $0.159^{a}$ \\
\hline Short bowel syndrome & 0 & 0 & \\
\hline Anastomotic failure & $6(10.5 \%)$ & $5(6.6 \%)$ & $0.617^{c}$ \\
\hline Catabolism & $3(5.3 \%)$ & $2(2.6 \%)$ & $0.65 \mathrm{I}^{\mathrm{c}}$ \\
\hline Impaired wound healing & $3(5.3 \%)$ & $3(3.9 \%)$ & $1.000^{c}$ \\
\hline Postoperative hemorrhage & $5(8.8 \%)$ & $2(2.6 \%)$ & $1.000^{c}$ \\
\hline Sepsis & $5(8.8 \%)$ & $3(3.9 \%)$ & $0.287^{c}$ \\
\hline Death & $3(5.3 \%)$ & 0 & $0.076^{c}$ \\
\hline Other & $8(14.0 \%)$ & $8(10.5 \%)$ & $0.538^{\mathrm{a}}$ \\
\hline Complication with reoperation & $9(15.8 \%)$ & $9(11.8 \%)$ & $0.510^{\mathrm{a}}$ \\
\hline Length of specimen $(\mathrm{cm})^{\mathrm{d}, \mathrm{e}}$ & $30(2-110)$ & $26.5(6-106)$ & $0.599^{b}$ \\
\hline Stoma, n (\%) & $13(22.8 \%)$ & $9(11.8 \%)$ & $0.092^{\mathrm{a}}$ \\
\hline Number of operations ${ }^{d}$ & $I(I-I I)$ & $I(I-6)$ & $0.31 \mathrm{I}^{\mathrm{b}}$ \\
\hline Number of hospitalizations ${ }^{d}$ & $I(I-I I)$ & $I(I-6)$ & $0.31 \mathrm{I}^{\mathrm{b}}$ \\
\hline Recurrence rate, $\mathrm{n}(\%)$ & 12 (9.4\%) & $10(13.2 \%)$ & $0.225^{\mathrm{a}}$ \\
\hline Death during long-term follow-up, n (\%) & & & $0.005^{c *}$ \\
\hline Alive & 45 (78.9\%) & $73(96.1 \%)$ & \\
\hline Dead & $9(15.8 \%)$ & $3(3.9 \%)$ & \\
\hline N.A. & $3(5.3 \%)$ & & \\
\hline
\end{tabular}

Notes: ${ }^{a}$ Chi square test, bMann-Whitney $U$ test, cFisher's exact test, ${ }^{d}$ median (range), epartially missing data; open $n=4$, laparoscopic $n=8$, *statistically significant.

Abbreviation: N.A., not available. 


\section{Complications}

The rate of complication was found to be low in both groups. The absolute majority of the patients in open (66.7\%) and the laparoscopic (77.6\%) group had no complications at all $(p=0.159)$. In both groups, anastomotic failure was found to show highest incidence (10.5\% in open vs. $6.6 \%$ in laparoscopic group) ( $p=0.617$ ). Likewise, there were no differences with regard to catabolism $(p=0.651)$, impaired wound healing ( $p=1.000)$, postoperative hemorrhage $(p=1.000)$ and postoperative sepsis $(p=0.287)$. All aforementioned complications were each observed in less than $5 \%$ in both groups.

We did not find any statistically significant difference with respect to postoperative death although there was a tendency toward better survival in the laparoscopic group. While all patients in the laparoscopic group survived, there were five deaths in the open surgery group. This trend was associated with late postoperative mortality in the open surgery group. Nevertheless, this difference did not reach statistical significance $(p=0.074)$. There were also no differences in the rates of redo-surgery between the groups $(p=0.510)$.

\section{Length of specimen/stoma}

There were no differences between the lengths of the specimens between the two groups $(p=0.599)$. Median lengths of the specimens in open and laparoscopic groups were 30 and $26.5 \mathrm{~cm}$, respectively. There were no differences with respect to the distribution of the values around the median in the two groups. In addition, the shortest $(2 \mathrm{~cm}$ in open and $6 \mathrm{~cm}$ in laparoscopic group) and the longest specimens $(110 \mathrm{~cm}$ in open and $106 \mathrm{~cm}$ in laparoscopic group) were absolutely comparable. Patients with open surgery had a slightly higher prevalence of a stoma than that of patients in laparoscopic group (22.8\% vs. $11.8 \%$, respectively). This difference was not statistically significant.

\section{Disease recurrence}

During the follow-up period, $9.4 \%$ of the patients in the open and $13.2 \%$ in the laparoscopic group had disease recurrence $(p=0.225)$.

\section{Testing of hypotheses $2 a$ and $b$}

Patients in laparoscopic group had a statistically significant shorter postoperative length of hospital stay with median 2 days less than that in the open surgery group. Therefore, hypothesis 2 a must be accepted.

There were no differences with respect to the rate of complications or disease recurrence, creation of stoma, and mortality in the short-term follow-up between the two therapeutic approaches. Furthermore, the differences in incidence of postoperative deaths were not statistically significant. The only difference that was shown was superior long-term survival in the laparoscopic group. Therefore, hypothesis $2 \mathrm{~b}$ must be rejected.

\section{Discussion}

This study was not designed as a prospective randomized controlled trial, and because of the retrospective nature of the study, we analyzed only for differences between the two study groups. As shown by other authors the groups were significantly different with respect to the analyzed parameters. This bias may be associated with preselection by the surgeons with regard to clinical conditions and was corresponding to current guideline recommendations as well as the results of other study groups that investigated retrospective cohorts of patients with Crohn's disease. ${ }^{7,8}$

The main key point of laparoscopic surgery is the often very young age of the patients and the risk of surgical recurrence because of the chronic nature of the disease. ${ }^{9,10} \mathrm{In}$ addition, it is presumed that a laparoscopic access allows faster recovery and return to work. ${ }^{11}$ Another key point is that smaller incisions in laparoscopy result in smaller scars, less intra-abdominal adhesions, and a better cosmetic result than conventional open surgery., ${ }^{2,6,12,13}$ Another key point is the absence of comorbidities such as advanced congestive heart disease and chronic obstructive pulmonary disease that precluded a laparoscopic approach. ${ }^{14}$ These arguments are represented in the choice of technique in our cohort. The patients of the laparoscopic group were significantly younger than patients of the open surgery group. This difference is a potential bias but is also a sign for therapy according to guidelines.

Two large registry studies from the United States showed comparable differences with respect to age in their analyses. ${ }^{7,8}$ In one study, of the total 1,917 patients, the patients of open surgery group had median age of 42 years, whereas it was 37 years in the laparoscopic group. ${ }^{7}$ Similar results were obtained by the second study in which 50,000 patients were included with abdominal surgery due to Crohn's disease in their analysis. They obtained a median age of 42 years in patients with open surgery group and 38 years in laparoscopic group. Age $<35$ years was found to be an independent predictor for laparoscopic surgery. ${ }^{8}$

With respect to the urgency of operation, guideline recommendations were generally arguing pro-laparoscopy in planned operations. ${ }^{9,10,14-16}$ These recommendations can be supported by the results of this study. Only in 34 out of 104 
patients with planned resections, an open access surgery was used. Nevertheless, with a growing number of professionals with expertise in laparoscopic surgery, it is possible to perform laparoscopy even in patients with emergency presentation and recurrent disease. ${ }^{1}$

Disease severity was found to be different between the two groups. Patients who underwent open resections were older and had significantly greater disease severity than that of young patients. They experienced fever more often and demonstrated elevated laboratory parameters. Moreover, the indications for open surgery were significantly more often sepsis, perforation, and peritonitis than that of laparoscopic group; this led to more emergency operations in the open surgery group. This bias is understandable taking the contraindications for laparoscopic surgery into account. These contra-indications for laparoscopic surgery were summarized by a recent meta-analysis. Septic shock, hemodynamic instability, and fecal peritonitis after perforation were identified as contra-indications for laparoscopic surgery. ${ }^{14}$ Another retrospective study that analyzed a national database from the National Surgical Quality Improvement Program showed that in 1,917 patients with ileocecal resection, patients with open resection were significantly older and more severely ill than that of patients in a laparoscopic group. ${ }^{7}$

The proportion of patients undergoing open resections decreased during the study period. On the one hand, this may be attributable to the achievements in conservative therapy, new medications, and less emergency. On the other hand, surgical skills have also improved during the study period. These developments and the absolute comparability of the laparoscopic approach in complex patients with Crohn's disease was also shown by several other study groups. ${ }^{15-21}$ Complex cases were defined as fistulous courses with intra-abdominal abscess or fistula and recurrent disease..$^{15} \mathrm{~A}$ meta-analysis of the aforementioned studies has shown that the laparoscopic approach could be performed on patients with fistulous and recurrent disease as well as on patients with prior surgery with potential intra-abdominal adhesions. The main advantage of laparoscopy is the prevention of intra-abdominal adhesions thus facilitating possible future surgical interventions. ${ }^{22}$ Growing expertise in laparoscopic surgery was analyzed by a meta-analysis which demonstrated almost identical duration of operation in laparoscopic and open surgery. ${ }^{9}$

Two large retrospective registry studies from the United States analyzed operations in patients with Crohn's disease. One group used data of 50,000 patients from all over the United States, whereas the other focused on 335 patients with Crohn's disease who underwent laparoscopic surgery at a single institution. Both studies identified a higher proportion of women in the laparoscopic group (54\%) ${ }^{8,20}$ The proportion of women in this study was found to be even higher (63\%). While a larger analysis on 50,000 patients was able to show using a multiple regression model that female gender was an independent predictor for laparoscopic surgery, we were not able to reproduce the same result in this study. This difference might be attributable to a smaller patient number in our cohort than the aforementioned study.

Ileocecal resection with a prevalence of $50 \%$ of all operations is the surgical therapy most often performed on patients with Crohn's disease. ${ }^{10,23}$ The results of this study that showed $50 \%$ ileocecal resections in the laparoscopic and the open surgery group were corresponding to the aforementioned studies and another single-center trial that involved $49 \%$ ileocecal resections in 335 laparoscopic surgeries. ${ }^{20}$ In a longterm follow-up study of patients with ileocecal resection, it was shown that the laparoscopic approach was superior with regard to body image and cosmesis and less incisional hernias and bowel obstruction. ${ }^{2}$

The bowel resection was the first abdominal surgery in both patient groups. Only a few patients had minor operations because of anal fistulas. With respect to these prior surgeries, there were no statistically significant differences between the groups. Because of the inclusion criteria in this study, it is logical that only patients with the initial operation are included in the analysis, but also the results of other study groups are based upon patients that underwent their first resection in the respective cohorts. ${ }^{20,24}$ Thus, our results are comparable to the available data.

Furthermore, with respect to duration of the disease there were no statistically significant differences in the results. Both groups had a median duration of disease of 5 years. We identified patients in both groups who had undergone an operation almost immediately after the first diagnosis of Crohn's disease, whereas others had a history of the disease of up to 30 years. The early operation in isolated ileocecal Crohn's disease was shown to be associated with a significantly better long-term outcome with less surgical recurrence for both open and laparoscopic operations. ${ }^{2}$ We did not observe an effect on the distribution and time of resection in the laparoscopic and the open surgery group. During the entire follow-up period, patients underwent early operation in both groups without significant differences between the groups.

A longer duration of the disease that might be associated with a more complex course of the disease and more adhesions did not result automatically in an open operation. Other authors found similar results in their retrospective 
cohorts with a median duration of the disease between 6.5 and 10 years. ${ }^{8,20,24,25}$ There were no differences with respect to the type of operation, number of operations, and gender in this study, but patients with open resections were significantly older and had greater disease severity than that of young patients. With respect to the composition of the study groups, we were able to show strong similarities with the cohorts of other studies. This is a strong indicator for a representative sample of the clinical reality.

\section{Length of stay}

Previous studies have generated data that are supportive toward the implementation of laparoscopic surgery compared to open resections. A variety of different studies described a decreased duration of hospitalization of around 1-3 days. ${ }^{6-8,11,13,16,26-28}$ We analyzed our data to confirm if the length of stay was also shorter in the laparoscopic group.

According to our results, the median postoperative stay was 2 days longer in the open surgery group than that of laparoscopic group. This difference was statistically significant $(p<0.001)$. Several meta-analyses were able to show similar results. The difference between open and laparoscopic resections was also 2 days in these analyses., ${ }^{9,10,29-31}$ This could be due to more severe abdominal trauma, more tissue damage, and prolonged intestinal paralysis in open surgery than that of laparoscopic surgery, which is often cited by other authors. ${ }^{14}$ A difference with respect to postoperative stay may thus be expected because of the choice of the intervention itself. Taking the differences with regard to age and disease severity into account, the difference of 2 days only seems to be relatively small.

It must be considered that even some of the randomized controlled trials with regard to the aforementioned discrepancy had a certain bias. ${ }^{13,27}$ On the one hand, none of the studies was blinded, which may have facilitated earlier discharge of patients who underwent laparoscopic surgery because of certain expectations. On the other hand, Milsom et al excluded patients from the study after a diagnostic laparoscopy if a laparoscopic approach was not suitable for the patients and conversion to open surgery was needed. ${ }^{27} \mathrm{~A}$ retrospective analysis of the data from the National Surgical Quality Improvement Program, which was able to show higher age and greater disease severity in the open surgery group, statistically controlled for these differences and showed a difference in postoperative hospitalization of 1 day only. ${ }^{7}$ Because we did not control for age and comorbidities in our study, the observed differences in postoperative hospitalization may be too pronounced; nevertheless, our study supports the advantages of laparoscopy with respect to postoperative length of stay.

\section{Postoperative outcome}

There is inconsistent data on postoperative outcome parameters except the length of postoperative hospital stay. Several authors observed a superiority of laparoscopy with respect to rates of complication and disease recurrence. These single center results were not confirmed in meta-analyses because of small differences between patients undergoing open and laparoscopic surgery without reaching statistical significance. In most studies no differences were found; laparoscopy was hence considered equivalent to open surgery by most authors. Furthermore, with respect to rates of stoma and peri- and postoperative mortality, both groups did not demonstrate superiority over the other. Hence, we analyzed our data with regard to possible differences between the two groups.

With respect to perioperative complications, two randomized controlled trials showed advantages for the laparoscopic approach. Both studies involved 30 patients for both the open and the laparoscopic access. ${ }^{13,27}$ However, the differences described were small and of questionable statistical significance. Milsom et al observed differences with regard to wound infections without reaching statistical significance. No differences were described in major complications as for example, abscesses or complications that needed re-operations. ${ }^{27}$

Maartense et al showed statistically significant differences for both minor and major (10\% vs. 33\%) complications during the comparison of open and laparoscopic approach. ${ }^{13}$ Their results were put into question by a Cochrane analysis that dealt particularly with the two aforementioned studies. The Cochrane analysis investigated on different complications (wound infection, urinary tract infection, abscess, and re-operation) not as the overall but as individual complications, was not able to find any statistically significant differences. With respect to the complication rate no superiority for the laparoscopic access could be shown by the data included in the Cochrane analysis. ${ }^{32}$ We were not able to show any statistically significant differences with regard to complications of the surgical access. The complication rate in the open $(33.3 \%)$ and the laparoscopic (22.4\%) groups were not significantly different. The complication rate observed in our laparoscopic group was much higher than the $10 \%$ complications described by Maartense. The reason for the worse results at first sight may be that our patient groups 
were much larger with 57 open and 76 laparoscopic surgeries compared to 30 and 30 in aforementioned study. ${ }^{13}$ Thus, the smaller numbers in the aforementioned study may be an explanation for the divergent results.

Other meta-analyses included the results of nonrandomized controlled trials. Again the authors were not able to find any significant differences between the groups and were only able to show a tendency for advantages of the laparoscopic access..$^{9,10}$ Older retrospective case-matched studies did not observe any differences between the groups with respect to complication rates. ${ }^{33,34}$ Recent registry studies, which analyzed national databases, were able to find significant differences in minor and major complications only after statistically adjusting for severity of the disease and age. ${ }^{7,8}$ These results may be interpreted with a growing expertise in laparoscopic surgery and associated lower complication rates.

The two patient groups in our study showed no statistically significant differences with regard to the need for the creation of an enterostomy or the length of the resected bowel segments. A priori it could be expected that patients with more severe disease and perforations required more extended resections and more often the creation of an ostomy. Lesperance et al were able to show significantly higher prevalence of enterostomies in patients after open resection than that of laparoscopic resection ( $11 \%$ vs. $6 \%$, respectively). ${ }^{8}$ In our cohort, a tendency for more enterostomies was observed for laparoscopic surgery with $22.8 \%$ versus $11.8 \%$ in the open surgery group. Again the number of emergency interventions has to be kept in mind. Our results are supported by the studies of Maartense et al and Milsom et al who were not able to find any differences with respect to number of emergency interventions. The numbers of the patients of the present study and the studies of Maartense et al and Milsom et al are very small compared to the registry study of Lesperance. ${ }^{8,13,27}$ With the inclusion of more patients into our study a statistically significant difference may have resulted.

The surgical recurrence rate was relatively low (about $10 \%$ ). There were no statistically significant differences between the patient groups. Despite the fact that single patients of the open surgery group had to undergo up to 10 surgical resections due to recurrences, the recurrence rate was not different in the laparoscopic and open surgery groups. After the first surgical intervention, the absolute majority of patients did not need further surgery. These results are comparable with the follow-up data of randomized controlled trials. ${ }^{13,27}$ A low surgical recurrence rate was also described by the follow-up study of the randomized controlled study by Maartense et al. Eshuis et al showed that the surgical recurrence rates were $11.5 \%$ in the open surgery group and $6.9 \%$ in the laparoscopic group. ${ }^{2}$ This difference was also not statistically significant. The median follow-up duration was 6.7 years in that study. Higher recurrence rates were found during the analysis of the follow-up data of the Milsom-study. ${ }^{27}$ After a median follow-up of 10.5 years, other authors described surgical recurrence rates of $29 \%$ in the open and $28 \%$ in the laparoscopic group. ${ }^{35}$ Another study of patients from a nonrandomized clinical trial showed surgical recurrence rates of $23 \%$ for open and $22 \%$ for laparoscopic resections after follow-up of 8.5 years. ${ }^{36}$ Thus, longer the follow-up period was, higher the recurrence rates were in all three aforementioned studies independent of the type of operation. The greatest difference although not statistically significant was found in a retrospective study in 113 patients. A total of $9.5 \%$ (6/63) of the laparoscopic and $24 \%$ (12/50) of the open surgery group had surgical recurrence. As a potential bias, the median follow-up periods were significantly different (62.9 months for the laparoscopic and 81.8 months for the open surgery group). ${ }^{37}$

The difference in the follow-up periods between the two groups in this study was of statistical significance. The median follow-up duration for open surgery group was 9 years, whereas it was only 6 years for the laparoscopic group. Compared to the data of the previous studies, in this study, the surgical recurrence rate in the open surgery group was relatively low because the longer follow-up period might have led to a higher prevalence of disease recurrence. Furthermore, severity of the disease prior to surgical therapy did not seem to have an influence on the prevalence of surgical recurrence. It is difficult to give an interpretation for the low surgical recurrence rate. It may be attributable to the surgical techniques or a better postoperative follow-up by the collaborating gastroenterologists and the implementation of new anti-inflammatory and immunosuppressive therapies. We do not have complete follow-up data with respect to the different medications in the two groups especially with regard to the use of newer therapies involving biologicals. Therefore, our results are potentially biased with regard to this parameter. Nevertheless, it has to be kept in mind that the follow-up duration in the open surgery group was significantly longer than that of laparoscopic group, and there is still no difference in surgical recurrence rates although the patients undergoing laparoscopic surgery might have had a higher benefit from newer therapies that were implemented during the recruitment period of the study.

Furthermore, it has to be kept in mind that the patient numbers in all previous aforementioned studies and this study 
were not higher than 113 patients with the highest number in this study. Higher patient numbers may result in higher or even smaller recurrence rates.

We were able to show a statistically significant difference between the two groups with regard to long-term survival. During the follow-up, significantly more patients in the open surgery group died compared to the laparoscopic group. The other follow-up aforementioned studies did not observe similar differences in their cohorts. ${ }^{2,35,36} \mathrm{We}$, therefore, assess this difference as related to the higher median age of the patients of the open surgery group than that of laparoscopic group and not related to the operation and technique itself.

\section{Conclusion}

The data with respect to rate of complication are inconclusive. Because of the difficulties in the design and conduct of an adequately powered randomized controlled trial, it is not very likely that we will get more meaningful data in the near future. With the growing expertise in laparoscopic surgery, the minimally invasive approach is at least comparable to the open access surgery in elective patients and patients without perforation also with reference to the need for an enterostomy and recurrence rates.

The statistical methods of this study were reviewed by Dr. Claudia Hemmelmann from the Institute of Medical Biometry and Statistics of the University of Lübeck.

\section{Disclosure}

The authors report no conflicts of interest in this work.

\section{References}

1. Tavernier M, Lebreton G, Alves A. Laparoscopic surgery for complex Crohn's disease. J Visc Surg. 2013;150(6):389-393.

2. Eshuis EJ, Slors JF, Stokkers PC, et al. Long-term outcomes following laparoscopically assisted versus open ileocolic resection for Crohn's disease. Br J Surg. 2010;97(4):563-568.

3. Ha FJ, Thong L, Khalil H. Quality of life after intestinal resection in patients with Crohn disease: a systematic review. Dig Surg. 2017;34(5): 355-363.

4. Fazio VW, Marchetti F, Church M, et al. Effect of resection margins on the recurrence of Crohn's disease in the small bowel. A randomized controlled trial. Ann Surg. 1996;224(4):563-571; discussion 571-3.

5. Buchanan GN, Owen HA, Torkington J, Lunniss PJ, Nicholls RJ, Cohen CR. Long-term outcome following loose-seton technique for external sphincter preservation in complex anal fistula. Br J Surg. 2004;91(4):476-480.

6. Sica GS, Biancone L. Surgery for inflammatory bowel disease in the era of laparoscopy. World J Gastroenterol. 2013;19(16):2445-2448.

7. Lee Y, Fleming FJ, Deeb AP, Gunzler D, Messing S, Monson JR. A laparoscopic approach reduces short-term complications and length of stay following ileocolic resection in Crohn's disease: an analysis of outcomes from the NSQIP database. Colorectal Dis. 2012;14(5):572-577.

8. Lesperance K, Martin MJ, Lehmann R, Brounts L, Steele SR. National trends and outcomes for the surgical therapy of ileocolonic Crohn's disease: a population-based analysis of laparoscopic vs. open approaches. J Gastrointest Surg. 2009;13(7):1251-1259.
9. Aarons CB. Laparoscopic Surgery for Crohn disease: a brief review of the literature. Clin Colon Rectal Surg. 2013;26(2):122-127.

10. Maggiori L, Panis Y. Laparoscopy in Crohn's disease. Best Pract Res Clin Gastroenterol. 2014;28(1):183-194.

11. Alabaz O, Iroatulam AJ, Nessim A, Weiss EG, Nogueras JJ, Wexner SD. Comparison of laparoscopically assisted and conventional ileocolic resection for Crohn's disease. Eur J Surg. 2000;166(3):213-217.

12. Dunker MS, Stiggelbout AM, van Hogezand RA, Ringers J, Griffioen G, Bemelman WA. Cosmesis and body image after laparoscopic-assisted and open ileocolic resection for Crohn's disease. Surg Endosc. 1998;12(11): 1334-1340.

13. Maartense S, Dunker MS, Slors JF, et al. Laparoscopic-assisted versus open ileocolic resection for Crohn's disease: a randomized trial.. Ann Surg. 2006;243(2):143-149; discussion 150-153.

14. Holder-Murray J, Marsicovetere P, Holubar SD. Minimally invasive surgery for inflammatory bowel disease. Inflamm Bowel Dis. 2015;21(6):1443-1458.

15. Goyer P, Alves A, Bretagnol F, Bouhnik Y, Valleur P, Panis Y. Impact of complex Crohn's disease on the outcome of laparoscopic ileocecal resection: a comparative clinical study in 124 patients. Dis Colon Rectum. 2009;52(2):205-210.

16. Holubar SD, Dozois EJ, Privitera A, et al. Laparoscopic surgery for recurrent ileocolic Crohn's disease. Inflamm Bowel Dis. 2010;16(8): 1382-1386.

17. Brouquet A, Bretagnol F, Soprani A, Valleur P, Bouhnik Y, Panis Y. A laparoscopic approach to iterative ileocolonic resection for the recurrence of Crohn's disease. Surg Endosc. 2010;24(4):879-887.

18. Chaudhary B, Glancy D, Dixon AR. Laparoscopic surgery for recurrent ileocolic Crohn's disease is as safe and effective as primary resection. Colorectal Dis. 2011;13(12):1413-1416.

19. Hasegawa H, Watanabe M, Nishibori H, Okabayashi K, Hibi T, Kitajima M. Laparoscopic surgery for recurrent Crohn's disease. Br J Surg. 2003;90(8):970-973.

20. Nguyen SQ, Teitelbaum E, Sabnis AA, Bonaccorso A, Tabrizian P, Salky B. Laparoscopic resection for Crohn's disease: an experience with 335 cases. Surg Endosc. 2009;23(10):2380-2384.

21. Wu JS, Birnbaum EH, Kodner IJ, Fry RD, Read TE, Fleshman JW. Laparoscopic-assisted ileocolic resections in patients with Crohn's disease: are abscesses, phlegmons, or recurrent disease contraindications? Surgery. 1997;122(4):682-688; discussion 688-689.

22. Spinelli A, Sacchi M, Bazzi P, Leone N, Danese S, Montorsi M. Laparoscopic surgery for recurrent Crohn's disease. Gastroenterol Res Pract. 2012;2012:381017.

23. Louis E, Collard A, Oger AF, Degroote E, Aboul Nasr El Yafi FA, Belaiche J. Behaviour of Crohn's disease according to the Vienna classification: changing pattern over the course of the disease. Gut. 2001;49(6):777-782.

24. Holubar SD, Dozois EJ, Privitera A, Pemberton JH, Cima RR, Larson DW. Minimally invasive colectomy for Crohn's colitis: a single institution experience: Inflamm Bowel Dis. 2010;16(11):1940-1946.

25. Umanskiy K, Malhotra G, Chase A, Rubin MA, Hurst RD, Fichera A. Laparoscopic colectomy for Crohn's colitis. A large prospective comparative study. J Gastrointest Surg. 2010;14(4):658-663.

26. Bemelman WA, Slors JF, Dunker MS, et al. Laparoscopic-assisted vs. open ileocolic resection for Crohn's disease. A comparative study. Surg Endosc. 2000;14(8):721-725.

27. Milsom JW, Hammerhofer KA, Böhm B, Marcello P, Elson P, Fazio VW. Prospective, randomized trial comparing laparoscopic vs. conventional surgery for refractory ileocolic Crohn's disease. Dis Colon Rectum. 2001;44(1):1-8; discussion 8-9.

28. Moloo H, Haggar F, Coyle D, et al. Hand assisted laparoscopic surgery versus conventional laparoscopy for colorectal surgery. Cochrane Database Syst Rev. 2010;(10):CD006585.

29. Rosman AS, Melis M, Fichera A. Metaanalysis of trials comparing laparoscopic and open surgery for Crohn's disease. Surg Endosc. 2005;19(12): $1549-1555$.

30. Tan JJ, Tjandra JJ. Laparoscopic surgery for Crohn's disease: a metaanalysis. Dis Colon Rectum. 2007;50(5):576-585. 
31. Tilney HS, Constantinides VA, Heriot AG, et al. Comparison of laparoscopic and open ileocecal resection for Crohn's disease: a metaanalysis. Surg Endosc. 2006;20(7):1036-1044.

32. Dasari BV, McKay D, Gardiner K. Laparoscopic versus Open surgery for small bowel Crohn's disease. Cochrane Database Syst Rev. 2011;(1): CD006956.

33. Benoist S, Panis Y, Beaufour A, Bouhnik Y, Matuchansky C, Valleur P. Laparoscopic ileocecal resection in Crohn's disease. Surg Endosc Interv Tech. 2003;17(5):814-818.

34. Young-Fadok TM, HallLong K, McConnell EJ, Gomez Rey G, Cabanela RL. Advantages of laparoscopic resection for ileocolic Crohn's disease. Improved outcomes and reduced costs. Surg Endosc. 2001;15(5):450-454.
35. Stocchi L, Milsom JW, Fazio VW. Long-term outcomes of laparoscopic versus open ileocolic resection for Crohn's disease: follow-up of a prospective randomized trial. Surgery. 2008;144(4):622-627; discussion 627-8.

36. Eshuis EJ, Polle SW, Slors JF, et al. Long-term surgical recurrence, morbidity, quality of life, and body image of laparoscopic-assisted vs. open ileocolic resection for Crohn's disease: a comparative study. Dis Colon Rectum. 2008;51(6):858-867.

37. Lowney JK, Dietz DW, Birnbaum EH, Kodner IJ, Mutch MG, Fleshman JW. Is there any difference in recurrence rates in laparoscopic ileocolic resection for Crohn's disease compared with conventional surgery? A long-term, follow-up study. Dis Colon Rectum. 2006;49(1):58-63.
Open Access Surgery

\section{Publish your work in this journal}

Open Access Surgery is an international, peer-reviewed, open access journal that focuses on all aspects of surgical procedures and interventions. Patient care around the peri-operative period and patient outcomes post surgery are key topics for the journal. All grades of surgery from minor cosmetic interventions to major surgical procedures are covered. Novel techniques and the
Dovepress

utilization of new instruments and materials, including implants and prostheses that optimize outcomes constitute major areas of interest. The manuscrip management system is completely online and includes a very quick and fair peer-review system, which is all easy to use. Visit http://www.dovepress.com testimonials.php to read real quotes from published authors. 